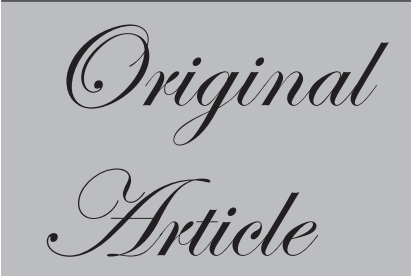

Department of Surgical Intensive Care,

${ }^{2}$ Department of Biostatistics,

${ }^{3}$ Department of Colorectal Surgery,

${ }^{4}$ Department of Infectious Diseases,

Christian Medical College and Hospital, Vellore, India.

Correspondence: Dr Pritish John Korula Email: pritishkorula@gmail.com

\section{Multidrug resistance in community acquired intra-abdominal infections}

\author{
Pritish John Korula ${ }^{1}$, Rajasekar Arumugam ${ }^{1}$, Visali \\ Jeyaseelan $^{2}$, Rajat Ragunath ${ }^{3}$, Kandasamy Subramani ${ }^{1}$, \\ Priscilla Rupali ${ }^{4}$
}

\section{ABSTRACT}

Background: Community Acquired Intra-Abdominal Infections (IAI's) secondary to hollow viscous perforations are not uncommon reasons for ICU admission in our country. It is unclear if high rates of Multidrug Resistant Organisms (MRO) are associated with adverse ICU outcomes in these infections.

Aim: To verify the impact of MRO in peritoneal isolates of patients with hollow viscous perforation on ICU outcomes

Methods: Retrospective cohort study of patients admitted to the SICU during a two-year period (Jan 2014 to Dec 2015) with community acquired IAI. Primary outcomes were ICU free stay differences between MRO positive and negative patients. Secondary outcomes were adverse outcomes (death or terminal discharge), hospital-free stay and complications.

Results: Among 2,581 patients admitted to the ICU over the study period (January 2014 to December 2015), 117 patients were admitted with community acquired hollow viscus perforation peritonitis. The most common cause was gastro-duodenal perforation (43.5\%). The most common empirical antibiotics were $\beta$-Lactam $\beta$ - Lactam inhibitor (BLBLIs) in $64.1 \%$ of the patients, while carbapenems were the most common postop antibiotics $(55.6 \%)$. Sixty-five percent of patients had source control performed with 24 hours of admission. Patients with MRO positive isolates as the causative pathogens presented relatively later (median of 3 days since symptom onset); MRO positivity did not impact on ICU length of stay. A univariate analysis revealed APACHE score and prolonged ICU and hospital stay were associated with adverse outcomes (death or terminal discharge). A multivariate analysis failed to show MRO as a risk factor for adverse ICU outcomes.

Conclusion: In a population with moderately high ESBL prevalence, community acquired perforation peritonitis with multidrug resistance pattern of organisms in isolates does not lead to adverse ICU outcomes, when the predominant empirical antibiotics were BLBLIs. Larger prospective and perhaps controlled studies may be needed to substantiate our findings.

KEYWORDS: Intra abdominal infections, community acquired, multidrug resistance. 


\section{Introduction}

Community Acquired Intra-abdominal Infections (IAIs) are a frequent cause of admission into a surgical Intensive Care Unit (ICU) in India owing to the high mortality and morbidity associated.1 Most series document gastroduodenal perforations with gram- negative organisms being the causative pathogens. ${ }^{1,2}$ With the increasing incidence of Multidrug resistant Organisms (MRO) in the community, it is becoming increasingly harder to predict what the empiric therapeutic options should be. ${ }^{3}$ The Infectious Disease Society of America (IDSA) recommends that the choice of empiric antibiotic for any community or hospital acquired infection should be based on local antibiotic resistance patterns. ${ }^{4}$

The use of inappropriate antibiotics in intraabdominal infections is likely to have adverse outcomes in some reports. ${ }^{5,6}$ In others, however, the antibiotic choice did not seem to impact adversely on outcomes. ${ }^{2,7,8,9}$ Quick and effective source control measures may have been responsible for good outcomes in instances where the antibiotic choice was inappropriate. ${ }^{10,11}$ However, some of these reports, particularly with regard to Indian data, were with reference to non-severe IAI's. ${ }^{9,8}$

It is unclear whether the outcomes are worse in the era of multidrug resistant organisms causing community acquired IAIs and there is hardly any data available from India. Therefore, we conducted a retrospective cohort study of patients admitted to the Intensive Care with community acquired Intra-abdominal infections so as to elaborate on the causative pathogens including MROs, the appropriateness of empiric and definitive antibiotic choices and the eventual outcomes.

\section{Methods}

Setting: A 13 bedded tertiary levelSurgical Intensive Care Unit (SICU)

Design: Retrospective cohort study of patients admitted to the SICU with community acquired Intra-abdominal Infections. The Institutional Review Board and Ethics committee of the institution approved the study proposal.

\section{Definitions}

Community acquired peritonitis: Was defined as a condition in which a patient presents with clinical features of peritonitis from the community without any prior healthcare exposure with intraoperative confirmation of a perforated viscus.

Multidrug-Resistant Organisms (MRO) Extended spectrum Beta-Lactamase (ESBL) producing organisms, Carbapenemase Resistant Organisms (CRO), Vancomycin Resistant Enterococcus (VRE) and Methicillin Resistant Staphylococcus Aureus (MRSA).

Antibiotic therapy was classified as $\beta$-Lactam $/ \beta$ Lactam inhibitor (BL-BLI) based therapy (PiperacillinTazobactam combinations or Cefaperazone/Sulbactam combinations), Carbapenem based therapy (which included Ertapenem or Meropenem) or Others (Cephalosporin or Penicillin based therapy in combination with Aminoglycosides or Fluoroquinolones).

Pre-operative Antibiotic: Antibiotic administered prior to surgical source control.

Post-operative antibiotic: Antibiotic administered after surgical source control.

ICU Free stay: Twenty-eight minus duration of ICU stay. ICU free stay equals zero if patient dies or is terminally discharged. (12)

Hospital free stay: Twenty-eight minus duration of Hospital stay. Hospital free stay equals zero if patient dies or is terminally discharged.

Post-operative complications: Defined as a composite of abdominal collections, wound dehiscence, readmissions or re-explorations.

Inappropriate antibiotic: Administration of an antibiotic to which an isolated organism was resistant.

Inclusion criteria: All adults ( $>15$ years of age) admitted to the ICU between Jan 2014 and Dec 2015 with features of an acute abdomen that was subsequently confirmed to be hollow viscous perforation surgically.

Exclusion Criteria: (a) Adults with Hospital acquired peritonitis (i.e. any peritonitis that was deemed to be hospital acquired or had been pre-treated elsewhere for peritonitis for more than 48 hours). The zone or time of separation between community acquired and hospital-acquired peritonitis was after admission to 
the hospital or when acquisition of the peritonitis was when patients were in the premises of the hospital. (b) Patients transferred or referred from other Hospitals were also excluded (c) Intra-abdominal infections other than hollow viscus perforations were also excluded. (d) We also excluded patients who underwent surgical source control but peritoneal fluid specimens were not sent for microbiological confirmation. (e) If yeast was a pathogen isolated in peritoneal fluid they were excluded as we felt that this group was totally different in terms of their pathogenesis as well as outcomes and would likely confound the results of the study.

Data collection: Two study investigators independently reviewed admissions to ICU during the study period, through the ICU database, hospital electronic record system and discharge summaries. The data collected was transcribed onto an excel sheet for analysis.

Primary outcome: Duration of ICU free stay (28 days minus duration of ICU stay; ICU free stay $=0$ if patient dies or is terminally discharged).

Secondary outcomes: Included "Adverse outcomes"- which was defined as a composite of death or terminal discharge, 'Hospital free stay' (28 days minus duration of hospital stay) and 'complications' (reoperations, readmission to ICU).

Data analysis: The required sample size to show a difference of about 2 ICU free days among patients with an MRO as the causative pathogen vs a non-MRO was found to be 40 in each arm (total of 80 subjects) with a variability of about 3 ICU free days at a power of $80 \%$ and $5 \%$ level of significance. The variability of 3 ICU free days was taken from retrospectively collected data in this ICU. The sample size was calculated using SAS 9.1.3 software. Frequencies and percentages were presented for categorical variables where as mean with SD were presented for continuous variables which are approximately symmetric in distribution while independent t-test was used to compare the outcome, where as median with IQR was presented for continuous variables which was not so symmetrical and the comparison of outcome was done using Mann Whitney U test.

The outcome was compared across categorical variables using Fisher's exact test. Penalized logistic regression was also used to find the risk factors for mortality. Penalized LR was done as the number of death and terminal discharge cases were low. P value $<0.05$ was considered as statistically significant. SPSS 16 was used for analyses.

\section{Results}

Among 2,581 patients admitted to the ICU over the study period (January 2014 to December 2015), 207 patients were admitted with acute peritonitis; of which 117 patients were admitted with community acquired hollow viscus perforation peritonitis. (Figure 1)

Young males chiefly populated the cohort (75.2\%) and they were moderately to severely ill (APACHE median score of 13) and presented after symptoms of about a median period of 2 days (Table 1). Most patients (80 of $117[68.3 \%]$ ) were taken up for surgery within 24 hours of hospital admission.

The commonest site for perforations was the upper gastro-intestinal region with 51 out of these patients presenting with gastro-duodenal perforations. (Table 1) The next common sites were small bowel (jejuno-ileal perforations, $\mathrm{N}=34$ ) and Appendicular $(\mathrm{N}=20)$. Among the jejuno-ileal perforations, a clear etiology was established in 20 of 34 cases, of which trauma (N-15), tuberculosis $(\mathrm{N}=3)$ and typhoid $(\mathrm{N}=2)$ contributed to each.

Out of the 117 patients that presented with acute perforation peritonitis from the community, 28 were excluded from the analysis as no cultures were sent $(\mathrm{N}=19)$ or as they had grown yeast $(\mathrm{N}=9)$ in peritoneal isolates (Figure 1 and 2).

Figure 1 shows the percentage peritoneal fluid samples for the 117 patients initially recruited. Among the bacterial isolates ( 89 in total), forty patients isolated MRO (45.6 \%). Most isolates in the MRO group (twenty four out of 40 patients $-60 \%$ ) were polymicrobial (mixtures of Enterobacteraciae species or Enterobacteraciae mixed with Enterococcus) (Table 1). Three patients of these 89 patients (3.3\%) isolated Carbapenemase Resistant Organisms (CRO) of which one concurrently had Vancomycin resistant Enterococcus (VRE). In one patient with poly microbial growth, VRE was again isolated as a pathogen (therefore 2 out the 89 
Figure 1

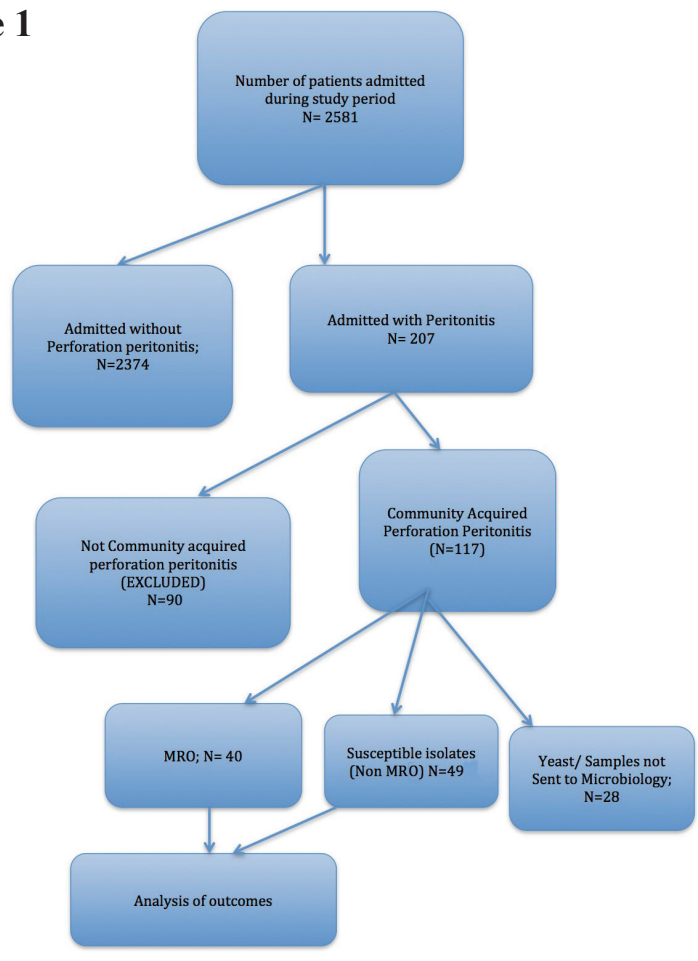

Figure 2

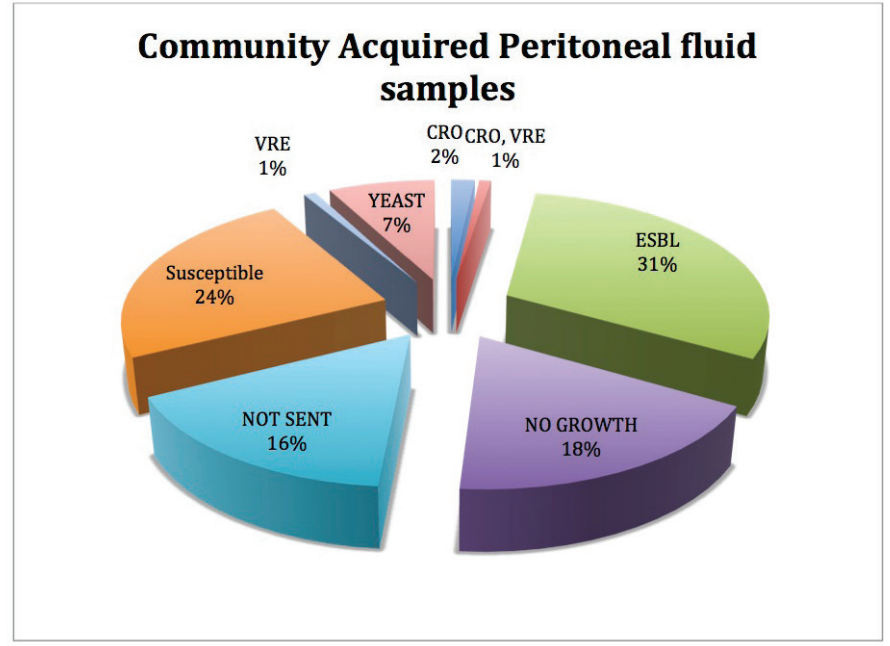

isolates were VRE positive). Non-MRO isolates were also similarly poly-microbial (sixteen of 28 susceptible - isolates [57.1\%]). Seventeen ESBL positive isolates $(47.2 \%)$ were BLBLI sensitive in vitro. (Table 1)

Blood cultures were taken in 106 of the 117 patients. One patient with a gastric perforation had candidemia at presentation (she was symptomatic for 5 days prior to her presentation to hospital). Only 3 other blood cultures were positive of which there was only one
Table 1: Baseline Characteristics and outcomes of all patients with hollow viscous perforations.

\begin{tabular}{|c|c|}
\hline $\begin{array}{l}\text { Total Number of patients } \\
\text { Males }\end{array}$ & $\begin{array}{l}117 \\
88\end{array}$ \\
\hline Age & 44.9 \\
\hline Symptomatic for (Median Days) & $2(1--4)$ \\
\hline $\begin{array}{l}\text { Site } \\
\text { Gastro--duodenal } \\
\text { Ileal } \\
\text { Appendicular } \\
\text { Jejunal } \\
\text { Colonic } \\
\text { Jejuno--ileal } \\
\text { Duodeno--jejunal } \\
\text { Rectal }\end{array}$ & $\begin{array}{l}51 \\
21 \\
20 \\
11 \\
10 \\
2 \\
1 \\
1\end{array}$ \\
\hline APACHE score-- Median andIQR & $13(6-19)$ \\
\hline 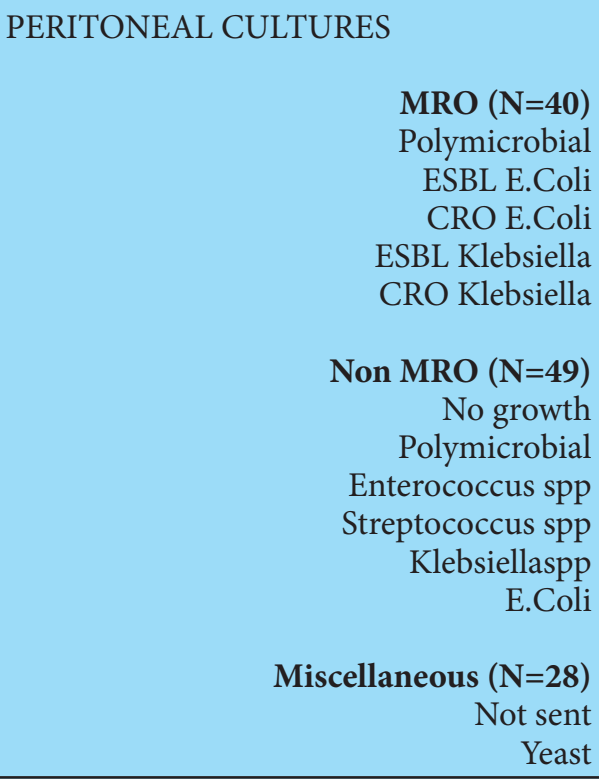 & \begin{tabular}{|l}
24 \\
13 \\
1 \\
1 \\
1 \\
\\
\\
21 \\
16 \\
4 \\
3 \\
3 \\
2 \\
\\
19 \\
9 \\
\end{tabular} \\
\hline $\begin{array}{l}\text { Number of ESBL isolates that were } \\
\text { Piperacillin--Tazobactam sensitive }\end{array}$ & $17 / 36(47.2 \%)$ \\
\hline Blood Culture Positive & $4 / 117(3.4 \%)$ \\
\hline $\begin{array}{l}\text { ICU free stay(28--days in ICU) } \\
\text { Median days (IQR) }\end{array}$ & $25(22--26)$ \\
\hline $\begin{array}{l}\text { Hospital Free stay (28--days in hospital) } \\
\text { Median days (IQR) }\end{array}$ & $15(8.5--18)$ \\
\hline $\begin{array}{l}\text { Death } \\
\text { Terminal discharge } \\
\text { Total }\end{array}$ & $\begin{array}{l}11 \\
11 \\
22(18.8 \%)\end{array}$ \\
\hline
\end{tabular}

\section{MRO (ESBL E.Coli) (Table 1).}

The commonest preoperative antibiotics were BLBLIs (75 of 117 patients- 64.1\%) whereas the most common post-operative antibiotic was a carbapenem (65 of $117-55.6 \%)$. The average duration of antibiotics therapy 
was 8 days. In addition to these classes of antibiotics, metronidazole was used pre-operatively in $104 / 117$ (89.7\%) patients and 87/117 (74.4\%) postoperatively and fluconazole was used empirically in post op patients exclusively in 44/117 (37.6\%). (Table 2)

Twenty-two of the 117 patients $(18.8 \%)$ had adverse outcomes (mortality or terminal discharge) out of which 11 were terminally discharged (Table 1).

On evaluation of the primary outcome, ICU free stay was a median of 25 days in the MRO group and 26 in patients with susceptible isolates (p- 0.08) (Table 3). Mortality and hospital free stay were similar in both groups.

Patients with MRO positive isolates as the causative pathogen presented relatively later (median of 3 days since symptom onset vs median of 1 day in non-MDRO group) (Table 3). They were not referred or transferred in from other hospitals, however we could not rule out antibiotic administration prior to their presentation to our institute.

The spectrum and number of post-operative complications (composite of abdominal collections, wound dehiscence, readmissions or re-explorations) that were present in the MRO group ( $\mathrm{N}=7)$ and Non MRO group $(\mathrm{N}=4)$ were similar (Table 4).

A post hoc univariate analysis identified APACHE score; ICU free stay and hospital free stay as variables associated with mortality. (Table 4) The days since symptom onset, site of perforation, inappropriate empirical antibiotic, presence of an MRO and date of surgery were not associated with mortality. A penalized logistic regression analysis of age, APACHE score, duration of symptoms, MRO positivity, inappropriate empiric antibiotics, surgery beyond 24 hours was performed. No identifiable risk factor for adverse outcomes could be determined.

\section{Discussion}

In a cohort of Intensive care patients admitted with severe community acquired intra-abdominal infections, we intended to verify the impact of multidrug resistance on outcomes.

In this cohort, we found that most were young
Table 2: Antibiotic use.

\begin{tabular}{l|l} 
Pre-op antibiotic- & $75(64.1 \%)$ \\
BLBLI & $10(8.5 \%)$ \\
Carbapenems & $32(27.4 \%)$ \\
\hline Others & $49(41.2 \%)$ \\
\hline $\begin{array}{l}\text { Post-Antibiotic- } \\
\text { BLBLI }\end{array}$ & $65(55.6 \%)$ \\
$\begin{array}{l}\text { Carbapenems } \\
\text { Carbapenem without }\end{array}$ & 35 \\
$\begin{array}{l}\text { Carbapenemem and } \\
\text { Glycopeptidecombination }\end{array}$ & 28 \\
$\begin{array}{l}\text { Carbapenem and Linezolidcombination } \\
\text { Others }\end{array}$ & 2 \\
\hline $\begin{array}{l}\text { Duration of Antibiotic use days- } \\
\text { MEDIAN (IQR) }\end{array}$ & $3(2.5 \%)$ \\
\hline $\begin{array}{l}\text { Metronidazole use (counted if given for } \\
\text { >50\% of duration of therapy) }\end{array}$ & $8(6-10)$ \\
$\begin{array}{l}\text { Pre-operative } \\
\text { Post -operative }\end{array}$ & $104 / 117(89.7 \%)$ \\
\hline $\begin{array}{l}\text { Empiric fluconazole use } \\
\text { (used only post op) }\end{array}$ & $87 / 117(74.4 \%)$ \\
\hline
\end{tabular}

males with moderate severity of illness who had mostly upper GI perforations. These findings are similar to other series from this country and demonstrate the difference in presentation from theWest. ${ }^{1}$

Patients presented after a median of 2 days of symptoms and a longer duration of symptoms predisposed to MRO positivity (although patients were screened for referral or transport from other hospitals, we could not rule out prior antibiotic administration by local practitioners).

The rate of bacterial multidrug resistance among isolates sent for microbiological culture testing of peritoneal fluid during surgery was slightly lower than other recent series; however, this rate is high enough to be concerned about. ${ }^{14}$ This moderately high MRO rate did not translate into poorer ICU outcomes for these patients even though they may have presented even later than the other patients in this cohort.

We found that the most common empirical antibiotics given preoperatively in our centre were BLBLIs (64.5\% of all cases) and carbapenems postoperatively (55.6\% of all cases). The post op predominance of carbapenems was perhaps due to the rate of ESBL resistance found in patient's intra-operative specimens sent for culture $(45.6 \%$ of bacterial specimens were 
Table 3: Clinical characteristics - MRO vs Non MRO isolates.

\begin{tabular}{|c|c|c|c|}
\hline & $\begin{array}{l}\text { MRO isolates (MDR isolates - } \\
\text { ESBL, CRO, VRE, MRSA) } \\
\mathrm{N}=40\end{array}$ & $\begin{array}{l}\text { Non MRO (Susceptible } \\
\text { isolates, No Growth on } \\
\text { isolates) } \\
\mathrm{N}=49\end{array}$ & P- Value \\
\hline Males & 29 & 38 & 0.76 \\
\hline $\begin{array}{l}\text { APACHE score-Median, } \\
\text { (IQR) }\end{array}$ & $13(8-19.5)$ & $10(5-17)$ & 0.17 \\
\hline $\begin{array}{l}\text { Duration of symptoms } \\
\text { Median days (IQR) }\end{array}$ & $3(1-5)$ & $1(1-3)$ & 0.02 \\
\hline Blood culture positive & 1 & 2 & 1.00 \\
\hline $\begin{array}{l}\text { Pre op Antibiotics } \\
\text { BLBLI } \\
\text { Carbapenems } \\
\text { Others } \\
\end{array}$ & $\begin{array}{l}30 \\
3 \\
7 \\
\end{array}$ & \begin{tabular}{|l}
39 \\
3 \\
10 \\
\end{tabular} & 0.93 \\
\hline $\begin{array}{l}\text { Antibiotic Used post op } \\
\text { BLBLI } \\
\text { Carbapenems } \\
\text { Others }\end{array}$ & $\begin{array}{c}17 \\
22 \\
1\end{array}$ & $\begin{array}{l}20 \\
28 \\
1\end{array}$ & 0.97 \\
\hline $\begin{array}{l}\text { Patients who had source } \\
\text { control < } 24 \text { hours }\end{array}$ & 27 & 31 & 0.85 \\
\hline $\begin{array}{l}\text { ICU free stay- Median days } \\
\text { (IQR) }\end{array}$ & $25(22-26)$ & $26(22-27)$ & 0.08 \\
\hline $\begin{array}{r}\text { DIED } \\
\text { Terminal Discharge } \\
\text { TOTAL }\end{array}$ & $\begin{array}{l}4 \\
1 \\
5 \\
\end{array}$ & $\begin{array}{l}3 \\
4 \\
7\end{array}$ & 1.00 \\
\hline $\begin{array}{l}\text { Hospital stay- Median } \\
\text { Days(IQR) }\end{array}$ & $12(7-15)$ & $11(8-14)$ & 0.39 \\
\hline $\begin{array}{l}\text { Hospital free stay- Median } \\
\text { Days (IQR) }\end{array}$ & $14(10.5-18)$ & $16(10.5-18.5)$ & 0.36 \\
\hline $\begin{array}{l}\text { Association with } \\
\text { complications } \\
\text { (COLLECTIONS/ } \\
\text { READMISSIONS/RE- } \\
\text { EXPLORATIONS) }\end{array}$ & 7 & 4 & 0.21 \\
\hline
\end{tabular}

ESBL). Metronidazole use was common for the purposes of anaerobe cover, however the use of this antimicrobial is not necessary while BLBLI's or carbapenems are being administered. ${ }^{13}$ Empirical fluconazole use was prevalent in $37.6 \%$ of cases. The empirical use of fluconazole is not recommended in community acquired peritonitis as per guidelines, however, if yeast is isolated in peritoneal isolates treatment is warranted. ${ }^{4}$

A univariate analysis demonstrated APACHE score to be associated with mortality which is in parallel with other studies on perforation peritonitis. ${ }^{2,6}$ The presence of an MRO was not associated with adverse outcomes. This finding is consistent with some studies. ${ }^{7,8,15}$ However, it was not consistent with some other studies. ${ }^{5,6}$

Also, duration of symptoms, site of perforation, inappropriate antimicrobial therapy, as well as day of surgery did not influence outcomes significantly.

Some of the reasons for the lack of clinically worse outcomes in patients with MRO's in our study could be the following-

a) Shorter duration of illness (with a median time of presentation of about 2 days).

b) Use of BLBLI's empirically may not have inferior efficacy to carbapenems in ESBL related infections; indeed many 
Table 4: Univariate data analysis.

\begin{tabular}{l|l|l|l} 
& $\begin{array}{l}\text { DEATH/Terminal discharge } \\
\mathrm{N}=12\end{array}$ & $\begin{array}{l}\text { ALIVE } \\
\mathrm{N}=77\end{array}$ & P- Value \\
\hline Sex - female & 7 & 21 & 0.16 \\
\hline AGE- Mean (SD) & $44.3(23.4)$ & $43.8(15.4)$ & 0.94 \\
\hline BMI (SD) & $24.6(2.3)$ & $23.4(3.5)$ & 0.29 \\
\hline APACHE-Median (IQR) & $21(9.8-25.5)$ & $11(5-17)$ & $<0.01$ \\
\hline $\begin{array}{l}\text { DURATION OF } \\
\text { SYMPTOMS: Median (IQR) }\end{array}$ & $2(1-4.3)$ & $2(1-4)$ & 0.66 \\
\hline $\begin{array}{l}\text { SITE of Perforation } \\
\text { Gastro Duodenal }\end{array}$ & 4 & 35 & 0.39 \\
\hline Day 1 Surgery & 17 & 63 & 0.5 \\
\hline MDRO positive & 5 & 35 & 1.00 \\
\hline $\begin{array}{l}\text { Inappropriate antibiotic } \\
\text { (Empirical) }\end{array}$ & 4 & 34 & 0.55 \\
\hline $\begin{array}{l}\text { Inappropriate post-op } \\
\text { antibiotic }\end{array}$ & 0 & 12 & 0.35 \\
\hline ALI (Acute lung injury) & 16 & 84 & 0.11 \\
\hline Inotropes & 7 & 39 & 0.53 \\
\hline AKI (Acute Kidney Injury) & 19 & 91 & 0.36 \\
\hline TPN requirement & 16 & 80 & 0.17 \\
\hline $\begin{array}{l}\text { ICU stay (days) : Median } \\
\text { (IQR) }\end{array}$ & $4(2-7.3)$ & $2(1-4)$ & $<0.01$ \\
\hline Hospital stay & $7.5(3.8-15)$ & $12(9-15)$ & $<0.01$
\end{tabular}

isolates (47.2\%) were in vitro sensitive to BLBLIs. ${ }^{7,16}$

c) Rapid diagnosis and institution of source control measures (most patients in this cohort were operated with in a 24 hour period of presentation to the hospital)and only a minority of them had bacteremia (4 out of 106 blood cultures sent). ${ }^{10}$

d) Good Microbiological services and Intensive care practice that may have influenced change in therapy based on clinical status or culture-sensitivity reports. ${ }^{17,18}$

e) MDRO organisms may not always be as virulent as wild type organisms. ${ }^{19}$

If MRO positivity does not significantly influence outcome in community-acquired peritonitis, this may have implications on antimicrobial use specifically in relation to empirical carbapenem use for ESBL coverage.

Carbapenem conservation and rational use would potentially lead to reduced MRO rates in hospitals and ICUs and reduced cost of treatment for individual patients. Indeed, a policy of empirical carbapenem use in a population with predominant MRO rates may be actually counterproductive in the short and long term especially for infections that are deemed to have a reasonably quick turn-around time and where source control measures may be superior to antimicrobial use..$^{20}$ In a series of patients with low risk intra-abdominal infections (appendicitis) requiring surgery, Gupta et al found perioperative choice of antibiotics did not have a significant impact on outcomes despite an ESBL rate of 19 out of 40 patients (47.5 \%). ${ }^{9}$ Another report by Trivedi et al also had similar findings. ${ }^{8}$

These implications however do not imply that antimicrobial use has no role in community acquired intra-abdominal infections. Indeed,carbapenem use is warranted when the risks of an ESBL infection is high for an individual patient or when acuity of illness is so severe, that ESBL coverage is deemed to be beneficial while return of culture sensitivity reports are awaited. ${ }^{4,11,21}$ In this regard, ertapenem may have favourable characteristics as it has a narrower spectrum than other carbapenems, potentially reducing induction of resistance to non- 
fermenting gram negative bacteria that plague Intensive Care Units and Hospitals. ${ }^{22}$

Based on the results of this observational study, we find that BLBLI's are safe as empiric antibiotics in community acquired peritonitis requiring Intensive Care admission.

One of the limitations of our study is that it was retrospective and observational. However, our study is the first to document outcomes related to antimicrobial resistance in community-acquired peritonitis in our country.

Our study is possibly underpowered to detect an outcome difference in MRO versus non-MRO groups and our outcome analysis was post hoc.

Nevertheless, some the descriptive and analytical components of our study may be valuable in providing information to institutions and units in formulating policies or protocols regarding antibiotic prescription for community acquired peritonitis.

To summarise, in a population with moderately high ESBL prevalence, community acquired perforation peritonitis with multidrug resistance pattern of organisms in isolates does not lead to adverse outcomes when the predominant empirical antibiotics were BLBLIs. Larger prospective and perhaps controlled studies may be needed to substantiate our findings.

\section{References}

1. Jhobta RS, Attri AK, Kaushik R, Sharma R, Jhobta A. Spectrum of perforation peritonitis in India--review of 504 consecutive cases. World J Emerg Surg. 2006;1:26.

2. Ramakrishnaiah VPN, Chandrakasan C, Dharanipragadha K, Sistla S, Krishnamachari S. Community acquired secondary bacterial peritonitis in a tertiary hospital of South India: an audit with special reference to peritoneal fluid culture. Trop Gastroenterol Off J Dig Dis Found. 2012;33:275akris

3. Morrissey I, Hackel M, Badal R, Bouchillon S, Hawser S, Biedenbach D. A Review of Ten Years of the Study for Monitoring Antimicrobial Resistance Trends (SMART) from 2002 to 2011. Pharmaceuticals. 2013;6:1335tance

4. Solomkin JS, Mazuski JE, Bradley JS, Rodvold KA, Goldstein EJC, Baron EJ, et al. Diagnosis and management of complicated intra-abdominal infection in adults and children: guidelines by the Surgical Infection Society and the Infectious Diseases Society of America. Clin Infect Dis Off Publ Infect Dis Soc Am. 2010;50(2):133JS, M

5. Sturkenboom MC, Goettsch WG, Picelli G, in dley JS, Rodvold KA, Goldstein EJC, Baron EJ, et al. Ditial treatment of secondary intra-abdominal infections leads to increased risk of clinical failure and costs. Br J Clin Pharmacol. 2005;60:438ettsc

6. Li Y, An Ni Wa E, Mei Ke L, Xiao D, Xia Z. Analysis of the risk factors related to prognosis of severe intra-abdominal infection in surgical intensive care unit. Zhongguo Wei Zhong Bing Ji Jiu Yi Xue Chin Crit Care Med Zhongguo Weizhongbing Jijiuyixue. 2012;24:162ongg

7. Bhavnani SM, Ambrose PG, Craig WA, Dudley MN, Jones RN. Outcomes evaluation of patients with ESBLand non-ESBL-producing Escherichia coli and Klebsiella species as defined by CLSI reference methods: report from the SENTRY Antimicrobial Surveillance Program. Diagn Microbiol Infect Dis. 2006;54:231vnan

8. Trivedi M, Patel V, Soman R, Rodriguez C, Singhal T. The outcome of treating ESBL infections with carbapenems vs. non carbapenem antimicrobials. J Assoc Physicians India. 2012;60:28 V, S

9. Gupta N, Sohanlal T, Soman R, Shetty A, Rodrigues C. The relevance of ESBL producing isolates in patients surgically treated for acute appendicitis. J Assoc Physicians India. 2011;59:293N, S

10. MartMart Sohanlal T, Soman R, Shetty A, Rodrigues C. The relevance of ESBL producing isolates in patients surgically te Control in Patients With Severe Sepsis and Septic Shock. Crit Care Med. 2017;45:11-19.

11. Kurup A, Liau KH, Ren J, Lu M-C, Navarro NS, Farooka $\mathrm{MW}$, et al. Antibiotic management of complicated intraabdominal infections in adults: The Asian perspective. Ann Med Surg. 2014;3:857en J

12. Young P, Saxena M, Bellomo R, Freebairn R, Hammond $\mathrm{N}$, van Haren F, et al., HEAT Investigators, Australian and New Zealand Intensive Care Society Clinical Trials Group. Acetaminophen for Fever in Critically Ill Patients with Suspected Infection. N Engl J Med. 2015;373:22153y Cl

13. Brook I. Spectrum and treatment of anaerobic infections. J Infect Chemother Off J Jpn Soc Chemother. 2016;22:1)ook

14. Shree N, Arora BS, Mohil RS, Kasana D, Biswal I. Bacterial profile and patterns of antimicrobial drug resistance in intra-abdominal infections: current experience in a teaching hospital. Indian J Pathol Microbiol. 2013 ;56:388ee N.

15. Gupta P, Pendurthi MK, Modrykamien AM. Extended utilization of noninvasive ventilation for acute respiratory failure and its clinical outcomes. Respir Care. 2013;58: 778ta P. 
16. Harris PNA, Peleg AY, Iredell J, Ingram PR, Miyakis S, Stewardson AJ, et al. Meropenem versus piperacillintazobactam for definitive treatment of bloodstream infections due to ceftriaxone non-susceptible Escherichia coli and Klebsiella spp (the MERINO trial): study protocol for a randomised controlled trial. Trials. 2015;16:24.

17. Yuan S, Astion ML, Schapiro J, Limaye AP. Clinical Impact Associated with Corrected Results in Clinical Microbiology Testing. J Clin Microbiol. 2005 ;43:2188 S, A

18. Peterson LR, Hamilton JD, Baron EJ, Tompkins LS, Miller JM, Wilfert CM, et al. Role of Clinical Microbiology Laboratories in the Management and Control of Infectious Diseases and the Delivery of Health Care. Clin Infect Dis. $2001 ; 32: 60515 . \mathrm{R}$

19. Beceiro A, Tom Tomnical Microbiology Laboratories in the Management and Control of Infectious Diseases and the Delivery of Health? Clin Microbiol Rev. 2013;26:185eiro A

20. Rattan R, Allen CJ, Sawyer RG, Askari R, Banton KL, Claridge JA, et al. Patients with Complicated IntraAbdominal Infection Presenting with Sepsis Do Not Require Longer Duration of Antimicrobial Therapy. J Am Coll Surg. 2016;222:440tan

21. Tellor B, Skrupky LP, Symons W, High E, Micek ST, Mazuski JE. Inadequate Source Control and Inappropriate Antibiotics are Key Determinants of Mortality in Patients with Intra-Abdominal Sepsis and Associated Bacteremia. Surg Infect. 2015;16:785lor B

22. Zhanel GG, Wiebe R, Dilay L, Thomson K, Rubinstein E, Hoban DJ, et al. Comparative review of the carbapenems. Drugs. 2007;67:1027el GG. 